\title{
Predator occurrence and perceived predation risk determine grouping behavior in guanaco (Lama guanicoe)
}

\author{
Esperanza C. Iranzo ${ }^{1}$ (D) | Heiko U. Wittmer ${ }^{2}$ (D) | Juan Traba ${ }^{1}$ \\ Pablo Acebes $^{1}$ (D) | Cristina Mata ${ }^{1}$ (D) | Juan E. Malo ${ }^{1}$
}

\author{
${ }^{1}$ Terrestrial Ecology Group-TEG, \\ Departamento de Ecología, Facultad de \\ Ciencias, Universidad Autónoma de Madrid, \\ Madrid, Spain \\ ${ }^{2}$ School of Biological Sciences, Victoria \\ University of Wellington, Wellington, New \\ Zealand
}

\section{Correspondence}

Esperanza C. Iranzo, Terrestrial Ecology Group-TEG, Departamento de Ecología, Facultad de Ciencias, Universidad Autónoma de Madrid, Madrid, Spain.

Email: esperanza.iranzo@gmail.com

\section{Present address}

Esperanza C. Iranzo, Instituto de Ciencias de la Tierra y Ambientales de La Pampa INCITAP-CONICET, Facultad de Ciencias Exactas y Naturales, Universidad Nacional de La Pampa (UNLPam), Avda, Uruguay 151, 6300 Santa Rosa, La Pampa, Argentina

\section{Funding information}

Programa UAM-CEAL (Banco Santander); REMEDINAL 3CM network, Grant/Award Number: S2013/MAE-2719; Consejo Nacional de Investigaciones Científicas y Técnicas; Agencia Española de Cooperación Internacional para el Desarrollo,

Grant/Award Number: A/016431/08, A/024945/09 and A/9875/07; Ministerio de Educación, Cultura y Deporte, Grant/Award Number: AP2010-0330; Servicio Agrícola y Ganadero Chileno

Editor: J. Wright

\begin{abstract}
Grouping behavior of social ungulates may depend on both predator occurrence and perceived predation risk associated with habitat structure, reproductive state, and density of conspecifics. Over 3 years, we studied grouping behavior of guanaco (Lama guanicoe) families in Chilean Patagonia during the birthing season and determined their response to variation in predator occurrence and perceived predation risk (habitat structure, calf/adult rate, and density of conspecifics). We considered the effect of two predators, puma (Puma concolor) and culpeo fox (Lycalopex culpaeus). We measured two common (family group size and vigilance) and one novel (family group cohesion) behavioral responses of guanaco. Our results show that guanaco family groups adapted their grouping behavior to both predator occurrence and perceived predation risk. Larger family groups were found in open habitats and areas with high puma occurrence, while guanacos stayed in small family groups in areas with high shrub cover or low visibility. Group cohesion increased in areas with higher occurrence of pumas and culpeo foxes, and also increased in smaller family groups and in areas with low guanaco density. Vigilance (number of vigilant adults) was mainly related to group size and visibility, increasing in areas with low visibility, while residual vigilance (vigilance after removing the group-size effect) did not vary with the explanatory variables examined. Our results suggest that a mix of predator occurrence and perceived predation risk influences guanaco grouping behavior and highlights the importance of evaluating different antipredator responses together and considering all predator species in studies aimed at understanding ungulate behavior.
\end{abstract}

\section{KEYWORDS}

culpeo fox, group size, landscape of fear, puma, social organization, ungulates

\section{1 | INTRODUCTION}

Predation risk is one of the main factors that shape grouping behavior in ungulates (Jarman, 1974; Kie, 1999; Moll, Killion, Montgomery, Tambling, \& Hayward, 2016). Results from previous studies suggest that prey develop dynamic and complex grouping behaviors as antipredator strategies (Caro, Graham, Stoner, \& Vargas, 2004; Creel,
Schuette, \& Christianson, 2014; Moll et al., 2017; Périquet et al., 2017). Grouping behavior can respond to the presence of predators (risky places according to Moll et al., 2016, 2017; Table 1) or to conditions related to habitat structure, conspecific density, and group size that influence perceived risk (Laundré, Hernández, \& Altendorf, 2001; Table 1). Living in groups has additional demonstrable benefits, such as improved predator detection (Kie, 1999; Lima, 1995; Pulliam, 
TAB LE 1 Description of guanaco family group response variables and predictor variables

\begin{tabular}{|l|l|}
\hline $\begin{array}{l}\text { Response variables } \\
\text { Group size }\end{array}$ & Number of animals in a family group \\
\hline $\begin{array}{l}\text { Group cohesion } \\
\text { Vigilance }\end{array}$ & Density of guanacos within a group (number of guanacos/group area) \\
\hline $\begin{array}{l}\text { Predictor variables } \\
\text { Predator occurrence }\end{array}$ & Relative occurrence of puma derived from MaxEnt probability of presence models \\
\hline Puma occurrence & Relative occurrence of culpeo fox derived from MaxEnt probability of presence models \\
\hline Culpeo fox occurrence & Location of the family group within/outside Torres del Paine National Park \\
\hline Perceived predation risk & Percentage of shrub cover within a $50 \mathrm{~m}$ radius around the centroid of the group \\
\hline Zone & $\begin{array}{c}\text { Terrain roughness, presence of rocks, or other visual obstacles within a } 50 \mathrm{~m} \text { radius around the } \\
\text { Shrub coner }\end{array}$ \\
\hline Visibility & $\begin{array}{c}\text { Guanaco probability of presence according to MaxEnt model around each family group within a } 500 \mathrm{~m} \\
\text { radius }\end{array}$ \\
\hline Conspecific density & Number of calves regarding adults in a family group \\
\hline Chulengo/adult ratio &
\end{tabular}

1973), reduced probability of being predated once detected (dilution and confusion effects; Lehtonen \& Jaatinen, 2016), and less individual time allocated to vigilance (collective vigilance; Lima \& Dill, 1990; Childress \& Lung, 2003; Creel et al., 2014). Habitat structure can shape predator-prey interactions through changes in visibility and the presence of either cover refuges or escape impediments (Eccard, Meißner, \& Heurich, 2017; Jarman, 1974; Ripple \& Beschta, 2003). In this sense, habitat openness will set the maximum group size, while predation risk will limit the minimum size (Jarman, 1974). Finally, Moll et al. (2017) suggested that prey behavior and assessment of risk are modulated by the prevailing conditions (e.g., resource distribution, which also influences group size through intraspecific competition among group members for food; Jarman, 1974; Marino, 2010) and prey characteristics (e.g., presence of offspring, as calves usually are more vulnerable and the preferred prey for predators; Bank, Sarno, Campbell, \& Franklin, 2002; Childress \& Lung, 2003; Creel \& Winnie, 2005; Tambling et al., 2012; Table 1).

Guanacos (Lama guanicoe) are monomorphic ungulates native to South America. Guanacos have a polygynous resource-defense mating system, and their social organization varies over the course of a year (Franklin, 1982; González, Palma, Zapata, \& Marín, 2006). During the birthing season in late austral spring and early summer, the most common social unit is the family group. Family groups typically consist of a territorial male and several females with their offspring. While the social organization of guanacos has been the focus of much research (e.g., Acebes, Malo, \& Traba, 2013; Franklin, 1982; Ortega \& Franklin, 1995; Schroeder et al., 2014), uncertainty remains regarding the influence of predation risk on group formation and the factors that determine composition of family groups. This is because previous studies regarding the effects of predation risk on grouping behavior in guanacos have either been conducted in areas with strongly contrasting predation risk (presence/absence of predators; Marino, 2010; Marino \& Baldi, 2008) or using humans as surrogates of predation risk (Taraborelli, Gregorio, Moreno, Novaro, \& Carmanchahi, 2012; Taraborelli et al., 2014). No studies have evaluated antipredator responses of guanacos to gradual variation in predator occurrence and perceived predation risk.

In the Chilean Patagonia, guanacos have two native predators: pumas (Puma concolor), the main predators, and culpeo foxes (Lycalopex culpaeus). While pumas prey on both young and adult guanacos (Bank et al., 2002; Elbroch \& Wittmer, 2012; Franklin, Johnson, Sarno, \& Iriarte, 1999), culpeo foxes are opportunistic predators of chulengos (guanaco calves up to 1 year in age; Novaro, Moraga, Briceño, Funes, \& Marino, 2009). Responses in social organization and group formation in guanacos should thus depend on predator species. In carnivore-ungulate systems, behavioral studies simultaneously considering the effect of more than one predator species are rare (Creel et al., 2017; Moll et al., 2017; Thaker, Vanak, Owen, Ogden, \& Slotow, 2010).

We evaluated the grouping behavior of guanaco family groups to predator occurrence and perceived predation risk during the birthing season in an area encompassing both a protected and a non-protected area. The birthing season is considered the most critical period due to the high predation risk experienced by chulengos (Bank et al., 2002). The management of the protected and unprotected area is different. First, wildlife is protected and livestock is excluded, while the surrounding non-protected area is dedicated to extensive livestock and wildlife is often persecuted. Antipredator behavior is a complex and multidimensional process. Univariate analyses may thus lead to contradictory results, and the simultaneous use of different behavioral indicators may help develop a comprehensive understanding of this behavior (Cappa, Campos, Giannoni, \& Andino, 2017; Creel et al., 2014; Lehtonen \& Jaatinen, 2016; Moll et al., 2017). For that reason, we quantified several antipredator grouping responses in order to provide a more accurate understanding of how guanacos respond to predation risk: group size, group 
vigilance, and group cohesion, the last being a novel and easy-tomeasure antipredator behavior (Table 1). Group cohesion is considered a measure of risk assessment (Peacor, 2003). In the presence of predators, groups of social species become more compact, probably due to the advantages of group defense and avoidance of predators (Lima \& Dill, 1990). Increasing group cohesion may improve early detection of an approaching predator and thus provide guanacos with longer response time (Taraborelli et al., 2012).

We considered responses to both predator occurrence (pumas and culpeo foxes) and perceived predation risk (habitat structure, protected vs. unprotected area, conspecific density and proportion of chulengos in each group). If guanacos respond to predator occurrence, we would expect larger, more cohesive groups as well as higher vigilance in areas with higher probability of encounter with a predator (Table 2). On the other hand, if guanacos respond to perceived predation risk, which is mainly determined by habitat structure, we would expect smaller, more cohesive groups as well as higher vigilance rates in areas with higher shrub cover and low visibility, because these will be perceived as riskier habitats independent of predator occurrence (Table 2). Due to the large abundance of wildlife within the protected area, we expected larger, more cohesive and more vigilant groups within it than in the non-protected area (Table 2). A higher chulengos/adult ratio potentially increases the perceived risk because chulengos are the preferred predator's prey (Franklin et al., 1999). Thus, we expected an increase in group cohesion and vigilance with increasing proportion of chulengos (Table 2). Finally, it has been suggested that conspecific density relaxes perception of risk through intraspecific communication and risk detection at large distances (Creel et al., 2017; Donadio \& Buskirk, 2016). We thus also expected an increase in group cohesion and vigilance in areas with lower conspecific density (Table 2).

\section{MATERIAL AND METHODS}

\section{1 | Study area}

We conducted our study in the Comuna Torres del Paine $\left(51^{\circ} 3^{\prime} \mathrm{S}\right.$; $72^{\circ} 55^{\prime} \mathrm{W}$ ) in the Última Esperanza Province, Region of Magallanes, Chile. Study area covered approximately $1090 \mathrm{~km}^{2} ; 284 \mathrm{~km}^{2}$ were located within Torres del Paine National Park (TPNP), and $806 \mathrm{~km}^{2}$ were outside the protected area, corresponding to several private ranches (Figure 1). Annual rainfall in the area varies between 300 and $1000 \mathrm{~mm}$, and mean temperature ranges from $2.0^{\circ} \mathrm{C}$ in winter to $10.8^{\circ} \mathrm{C}$ in summer (Vidal \& Reif, 2011). Vegetation is dominated by steppe-like grasslands and shrublands (Pisano, 1974). TPNP is separated from surrounding ranches by a 1.2-m-high wire fence, which restricts livestock movements from ranches into the National Park but allows wildlife movements, although guanacos occasionally die entangled in it (Rey, Novaro, \& Guichón, 2012).

Guanacos are the most abundant large-bodied native herbivore in the study area. Estimated guanaco densities currently vary from 36.6 (within TPNP) to 8.8 (outside TPNP) individuals $/ \mathrm{km}^{2}$ (Iranzo et al., 2017). Other medium- to large-bodied native herbivores found 


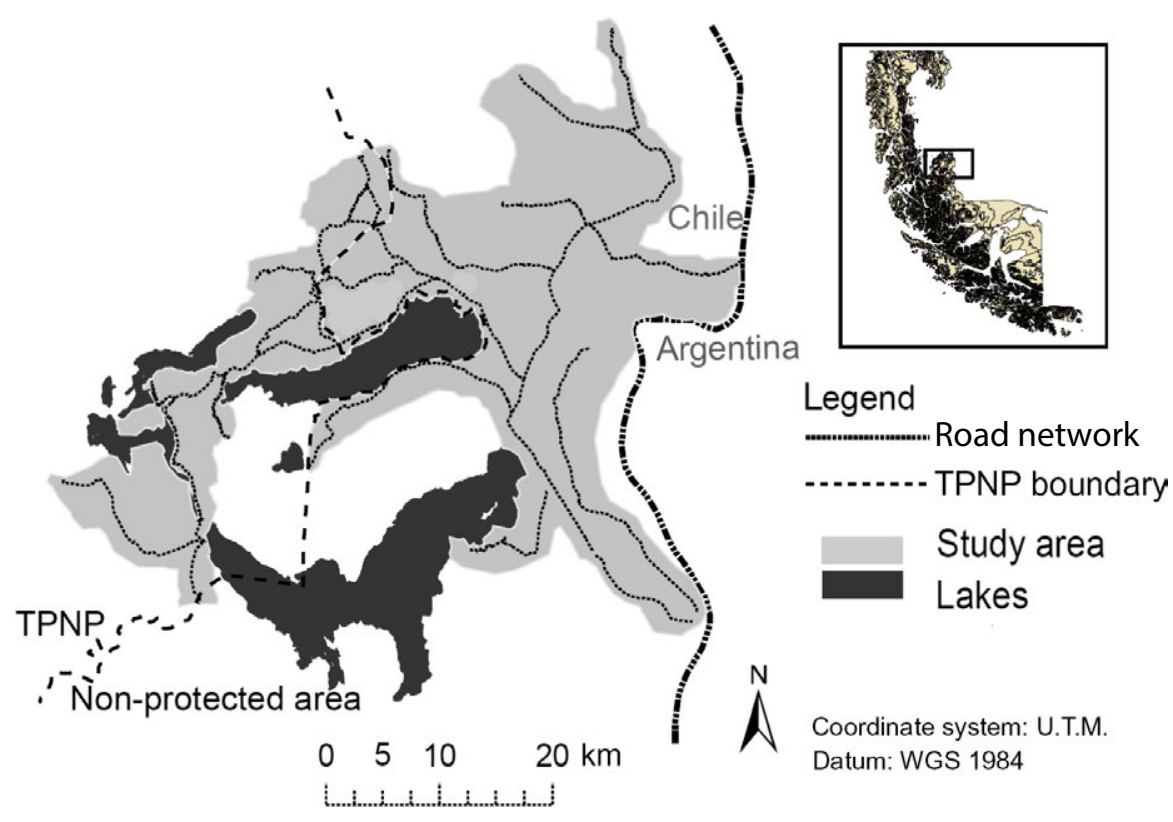

FIGURE 1 Study area and the road network at the surveyed area in the Comuna Torres del Paine (Magallanes Region, Chile) in our study area are lesser rhea (Pterocnemia pennata) and upland geese (Chloephaga picta), both of which occur at low densities compared to guanacos. Introduced European hares (Lepus europaeus) are present throughout the study area and are locally abundant. Pumas and culpeo foxes occur at variable densities throughout the study area. Reported puma densities within TPNP are high compared to density estimates from other areas of their distribution (Franklin et al., 1999; but see Rinehart, Elbroch, \& Wittmer, 2014) and decline toward surrounding areas (own unpublished data). Culpeo foxes within TPNP occur at an estimated density of 1.2 individuals $/ \mathrm{km}^{2}$ (Lucherini, 2016) and at a similar density in the surrounding areas (own unpublished data).

\subsection{Data collection}

We conducted surveys during the birthing season in December (i.e., during late Austral spring) of 3 consecutive years (2009, 2010, and 2011) to determine size, cohesion, and vigilance of guanaco family groups. Two survey teams equipped with binoculars carried out vehicle and foot-based surveys along the existing network of paths and roads in the study area (total transect length surveyed $=336.4 \mathrm{~km} /$ year) and recorded all guanacos (individuals and groups) they encountered. Researchers were trained to determine visual estimation criteria in a consistent way. In addition, to reduce possible bias, the members of teams were rotated daily. A detailed description of survey methodology is provided in Iranzo et al. (2013, 2017), and Traba, Iranzo, Carmona, and Malo (2017).

We recorded the GPS position for every family group detected and determined its size, composition (sex, and age classified as adult, juvenile, or chulengo) and location (within or outside protected area). To evaluate group cohesion (a measure of packing or animal density per family group), we visually estimated the occupation area (maximum length and width). Using instantaneous scan sampling, we quantified the number of adults with heads up (above the shoulder level) at the time of our first observation, avoiding any kind of disturbance by the observers, and used this number as an approximation of group vigilance (Childress \& Lung, 2003). To assess perceived predation risk, we visually estimated shrub cover and visibility within a $50 \mathrm{~m}$ radius around the centroid of the group. Visibility was assessed based on terrain roughness and the presence of rocks or other visual obstacles, and classified into three categories: high (no visual restriction in any direction), medium (reduced visibility in some direction), and low (low visibility in all directions). During surveys, we also recorded the location and size of bachelor groups, female groups, and solitary guanacos to estimate total guanaco density (Iranzo et al., 2017).

To determine the influence of both predators on guanaco behavior, we estimated their relative occurrences in the study area using two complementary methods. First, we conducted snow track surveys during austral winters of 2011 and 2012. Surveys were conducted by two observers walking 200-m linear transects, $5 \mathrm{~m}$ width, every $5 \mathrm{~km}$ along the same set of roads and paths used to survey guanacos (year 2011: $n=40$ transects covering $8 \mathrm{~km}$; year 2012: $n=54$ transects covering $10.8 \mathrm{~km}$ ). During surveys, we recorded all signs (i.e., feces, tracks) of puma and culpeo fox presence. Despite the mismatch between sampling periods, pumas and culpeo foxes occupy distinct home ranges and are relatively long-lived; we thus did not expect large differences in either space use or occurrence among years. Moreover, no noticeable changes in the state or management of the area were observed in the area along the sampling years. Home ranges of pumas in the study area vary between 19 and $84.5 \mathrm{~km}^{2}$ (Barrera, Soto, Cabello, \& Antúnez, 2010; see also Franklin et al., 1999) and remain in their home ranges year-round (Franklin et al., 1999). We thus considered winter surveys as a valid proxy of puma relative occurrence during summer. Culpeo fox home ranges in the area vary between 4.5 and $9.8 \mathrm{~km}^{2}$ (Johnson \& Franklin, 1994) 
and are also territorial species. Hence, the same assumption for relative occurrence was applied. We also deployed remote cameras to record predators along the road network used for guanaco surveys. Specifically, we installed scent stations (Long et al., 2003) every $5 \mathrm{~km}(n=40)$; each scent station was formed by three scent points separated each other by $500 \mathrm{~m}$. We used a small synthetic sponge (0.05 $\mathrm{m}$ above the ground) soaked with bobcat urine as a lure. We also used footprint traps around scent points. In addition, at the central scent point of each scent station, we placed a Cuddeback ${ }^{\circledR}$ Capture IR Digital camera (Cuddeback ${ }^{\circledR}$ Digital, Non Typical Inc., Park Falls, WI, USA) with the pyroelectric infrared (PIR) motion detection sensor focused to the center of the scent station, where the attractant was located. Each scent station was active $24 \mathrm{hr}$; this implies 40 camera-trapping nights (plus the corresponding 80 scent points). We combined both sampling methods to increase sampling size, finally reaching 49 detections for pumas and 66 for culpeo foxes. We then converted predator records from both surveys into estimates of probability of presence as a proxy of relative occurrence and predator encounter probability. We used MaxEnt software (Phillips, Anderson, \& Schapire, 2006; see below) to build models of probability of presence as this software provides a good fit with our type of data (sure presences coming from a combination of snow tracking and camera trapping obtained from an uneven sampling protocol).

\section{3 | Statistical analysis}

We used generalized linear mixed models (GLMM) to evaluate the responses of guanaco family groups to variation in both relative predator occurrence and perceived predation risk. We used group size, group cohesion, and vigilance as response variables. Group cohesion was calculated as the density of guanacos within a group (number of guanacos/group occupation area, where group occupation area is the area of the rectangle that contained the group in ha.). For group vigilance, we considered the number of vigilant adults in a group. We excluded the number of chulengos as they do not contribute to predator detection. Due to the potential effect of group size on vigilance, we evaluated the role of predator occurrence and perceived predation risk on residual vigilance (vigilance after removing the group-size effect; Data S1).

We evaluated each response variable as a function of the following set of explanatory variables related to perceived predation risk: percentage of shrub cover, visibility, conspecific density, and relative puma and culpeo fox occurrences. We analyzed the location of the groups to account for potential differences in guanaco behavior related to the protected area (within/outside it). In addition, we included the chulengo/adult ratio as an explanatory variable for group cohesion and vigilance analyses, group size for the group cohesion analysis, and group size and its quadratic term for vigilance analysis. Finally, we included year as a (intercept) random effect. Because of the limited number of groups recorded in areas with low visibility, we grouped medium and low visibility levels for our analysis.

To assess actual predation risk, we built a model aimed at estimating relative occurrence of pumas and culpeo foxes using data from our predator surveys. We built a model for each species using MaxEnt (Phillips et al., 2006). We used the presence of either predator as the response variable and a set of climatic and topographic variables as explanatory variables (Data S2 and Table S2). Climatic variables were obtained from WorldClim database and topographic variables from Digital Terrain Model ASTER GDEM (METI \& NASA). We used boosted regression trees to reduce the initial number of explanatory variables (Elith, Leathwick, \& Hastie, 2008) prior to building MaxEnt models (Data S2 and Table S3). Similarly, we used all guanaco observations to build a model of relative occurrence of guanacos as a proxy of conspecific density to determine how it affected perceived predation risk (Tables 1 and 2). We assigned conspecific density in a buffer of $500 \mathrm{~m}$ radius around each family group, as guanacos can reliable detect conspecific signals and calls of animals belonging to other groups within this distance (Donadio \& Buskirk, 2016).

We standardized explanatory variables prior to conducting GLMM. We used GLMM with a Poisson distribution and log link function for group size and vigilance, and LMM with a normal distribution for analysis of group cohesion. We used model averaging (Burnham \& Anderson, 2002) to estimate contributions of variables across the range of plausible models. We first built the complete set of possible models and we ranked them according to their AIC values. Then, we selected the plausible ones as those whose AIC weights were included in a $95 \%$ confidence interval set of models (for a similar approach, see Whittingham, Swetnam, Wilson, Chamberlain, \& Freckleton, 2005). We then applied model averaging over the selected set of models, obtaining for each predictor the weighted value of its estimators, the unconditional standard error based on Burnham and Anderson (2004) revised formula, and its $z$ and $p$-values to identify significant effects. We performed our analyses using R packages Ime4 (Bates, Maechler, Bolker, \& Walker, 2011), MuMIn (Barton, 2012), and MASS (Venables \& Ripley, 2002).

\section{3 | RESULTS}

We observed 314 families of guanacos over the 3 years of study. Family group size ranged from 2 to 60 individuals (mean \pm $\mathrm{SE}=14.6 \pm 0.6$ individuals), with a mean of $11 \pm 0.5$ adults, $0.5 \pm 0.1$ juveniles, and $3.1 \pm 0.2$ chulengos.

Variation in group size was explained by an averaged model including one variable significantly associated with occurrence of predators and two to perceived predation risk (Table 3, see also Data S3 and Table S4). According to the model, observed groups were larger at locations with high occurrence of pumas and smaller at locations with low visibility and with a higher proportion of shrub cover.

Mean group cohesion was $261.8 \pm 866$ animals/ha. Group cohesion was explained by an averaged model including two variables significantly associated with occurrence of predators and other two to perceived risk (Table 3, see also Data S3, and Table S5). According to the model, group cohesion significantly increased with relative occurrence of both pumas and culpeo foxes and decreased with group size and guanaco conspecific density. 
TAB LE 3 Variables (averaged) influencing guanaco family group size, cohesion, and vigilance

\begin{tabular}{|c|c|c|c|c|c|c|c|c|c|}
\hline & \multicolumn{3}{|c|}{ Group size } & \multicolumn{3}{|c|}{ Group cohesion } & \multicolumn{3}{|c|}{ Group vigilance } \\
\hline Intercept & 2.718 & 0.061 & $<.001$ & -5.086 & 0.138 & $<.001$ & -0.278 & 0.202 & .170 \\
\hline Puma occurrence & 0.143 & 0.020 & $<.001$ & 0.426 & 0.100 & $<.001$ & -0.012 & 0.077 & .874 \\
\hline Culpeo occurrence & 0.029 & 0.018 & .102 & 0.248 & 0.096 & .010 & 0.144 & 0.084 & .086 \\
\hline Visibility & 0.187 & 0.033 & $<.001$ & 0.045 & 0.172 & .794 & -0.391 & 0.124 & .002 \\
\hline Conspecific density & -0.001 & 0.020 & .942 & -0.468 & 0.106 & $<.001$ & -0.145 & 0.076 & .057 \\
\hline Group size & - & - & - & -0.372 & 0.081 & $<.001$ & 0.466 & 0.106 & $<.001$ \\
\hline Group size $^{2}$ & - & - & - & - & - & - & -0.081 & 0.041 & .045 \\
\hline
\end{tabular}

C/A ratio, chulengo/adult ratio. Model estimates, adjusted standard errors, and $p$-values are presented. Significant $p$-values are marked in bold.

Overall, mean group vigilance (of the total number of groups) was $10.20 \pm 0.01 \%$ of adults and juveniles, which corresponds to an average of $0.95 \pm 0.10$ vigilant animals per group ( $\min =0, \max =13$ ). In addition, $56.4 \%$ of groups were not vigilant upon first encounter while $43.6 \%$ of the groups contained at least one vigilant individual.

Observed differences in vigilance were explained by a model that included one variable associated with perceived predation risk (visibility), group size and its quadratic term, and guanaco conspecific density at a marginally significant level (Table 3, see also Data S3 and Table S6). According to the model, vigilance increased in areas of low visibility and with group size and decreased with the quadratic term of group size and guanaco conspecific density. Residual vigilance was only marginally affected by visibility (Data S1 and Table S1).

\section{4 | DISCUSSION}

Our results suggest that both predator occurrence and perceived predation risk affect grouping behavior of family groups. Thus, group size was influenced by occurrence of predators and by perceived predation risk associated with habitat structure. Group cohesion was related to both predator occurrence and perceived predation risk related to conspecifics, while vigilance was affected by visibility and group size.

As expected, predator occurrence affected group size and cohesion in guanacos, but contrarily to our predictions, it did not affect group vigilance. Specifically, guanaco family group size was positively associated with areas with greater relative puma occurrence, where guanacos may reduce individual predation risk through increases in group size (dilution and confusion effects; Hamilton, 1971; Lehtonen \& Jaatinen, 2016). Predator occurrence may be interpreted as a proxy of predator abundance and probability of encounter with a predator because abundance and occurrence are frequently related in carnivores (Linden, Fuller, Royle, \& Hare, 2017), although this entails some uncertainty. Aggregation and changes in prey group size as a response to risk have previously been reported in many herbivores (e.g., Banks, 2001; Creel et al., 2014; Moll et al., 2016, 2017). In the case of guanaco, Marino and Baldi (2014) reported larger families in populations coexisting with pumas than in predator-free reserves. Contrarily, the relative occurrence of culpeo fox, an occasional and opportunistic predator, had no effect on guanaco group size. Hence, these results point to a stronger influence of the main predator (puma) on guanaco grouping behavior. Moll et al. (2016) reported similar results for African ungulates and suggested that differences were likely related to the lethality and hunting efficacy of each predator. In addition, guanacos exhibited increased group cohesion as a response to an increased occurrence of both pumas and culpeo foxes. Increasing group cohesion may improve early detection of an approaching predator and thus provide guanacos with longer response time (Taraborelli et al., 2012). Thus, guanacos likely benefit from forming large and cohesive groups with increased detection of predators (collective vigilance hypothesis; Pulliam, 1973; Pulliam \& Caraco, 1984; Taraborelli et al., 2012).

Perceived predation risk partially affected guanaco group size, cohesion, and vigilance. As expected, group size of guanacos was larger in open habitats with high visibility. This is related to resource distribution (Jarman, 1974) and to increased conspecific detection in open areas (Gerard \& Loisel, 1995; Pays, Benhamou, Helder, \& Gerard, 2007). Moll et al. (2016) found similar effect sizes of habitat openness and predation risk in African ungulates, pointing to the important contribution of perceived risk on ungulate behavior (Moll et al., 2017). Acebes et al. (2013) also reported a similar pattern in the Argentinean Monte Desert, where food resources are extremely scarce. There, family groups of guanacos selected open low-risk, less productive areas during the breeding season. These results point to an evolutionary fixed pattern in the species: prioritization of reducing predation risk in the birthing period over the selection of areas with abundant food resources.

Group cohesion increased with a decrease in both group size and conspecific density, suggesting a "safer-feeling effect" on guanaco behavior: An increased perception of predation risk when group members are sparsely distributed and/or groups is isolated (Peacor, 
2003). Contrary to our expectations, shrub cover and visibility did not increase group cohesion. In this case, intragroup competition for resources (interference competition) could constrain family group size and distance among individuals, thus preventing the formation of large and cohesive groups in these habitats (Jarman, 1974; Marino, 2010). Thus, habitat structure and forage quality and availability may have influenced grouping behavior in guanacos together with perceived predation risk (Creel et al., 2014; Moll et al., 2016; Ripple \& Beschta, 2003).

The number of vigilant individuals was primarily affected by group size but also increased in areas with lower visibility. Neither predator occurrence nor the chulengo/adult ratio were included in top models explaining the number of vigilant individuals within groups. The strong influence of group size on vigilance points to the effect of "collective vigilance," one of the classical hypothesized benefits of living in groups (Pulliam, 1973; Pulliam \& Caraco, 1984; Taraborelli et al., 2012). According to the collective vigilance hypothesis, individuals can reduce the time spent in vigilance (and feed more), because in groups, vigilance is equivalent to or greater than a lone individual could afford to engage in. The inclusion of the quadratic term with negative estimator thus points to this release of vigilance allotment by individuals in larger groups. In this sense, the relationship between group size and number of vigilant adults was expected. The lack of relevant predictors explaining variation in residual vigilance (variation in vigilance unaccounted by variation in group size; Data S1) could suggest that vigilance in guanaco is a variable directly shaped by group size. However, we found different responses for group size and vigilance. We were thus unable to clarify whether residual vigilance was just "noise" or responded to other ecological factors, such as social monitoring, not included in the study. Contrary to our predictions, group cohesion and vigilance were not affected by the chulengo/adult ratio, despite chulengos being the preferred prey. These results could be related to the low time allocated to vigilance by females in family groups, in which the male is the main vigilant (Barri \& Fernández, 2011; Marino \& Baldi, 2008). Finally, we did not detect differences in guanaco grouping behavior associated with their location within or outside Torres del Paine National Park.

Interestingly, group cohesion has been sometimes included as an independent predictor for vigilance and antipredator response analyses (Marino \& Baldi, 2008; Taraborelli et al., 2012). However, to our knowledge, there are no studies including group cohesion as an antipredator response variable for carnivore-ungulate systems (see Lima \& Dill, 1990 or Peacor, 2003 for other study systems). Our findings suggest that understanding changes in group cohesion may complement traditional studies only looking at changes in group size as antipredator response and point to the importance of evaluating multiple responses in order to know species-specific antipredator behavior. Specifically, the response of group cohesion to predator occurrence, conspecific density, and group size suggests that guanacos are risk-sensitive and may adapt their individual distance to other group members according to actual and perceived predation risk.

In conclusion, our results suggest that grouping behavior is affected by multiple variables including response to predation risk and support previous suggestions that no single factor drives ungulate antipredator behavior. Predator occurrence, considered to reflect the predator abundance or probability of encounter with a predator, shaped guanaco grouping behavior and was approximately 10 times more important than shrub cover, which we considered to reflect the perceived predation risk (Laundré et al., 2001; Moll et al., 2017). However, it did not describe antipredator responses alone, showing the importance of the perceived predation risk as an antipredator behavior driver for ungulates, as reported by Creel et al. (2017). Responses to predation risk were also linked to the occurrence of different predator species, highlighting the importance of considering all predator species in studies aimed at understanding antipredator behavior of ungulates. The evaluation of several response variables contributed to a better understanding of ungulate antipredator grouping behavior. Finally, the observed responses were limited to family groups during the breeding season, and further research is necessary to confirm whether the observed patterns apply to other situations.

\section{ACKNOWLEDGEMENTS}

We thank all collaborators who participated in data collection, particularly M.A. Vukasovic, N. Fuentes, B.A. González, and D. Valencia. Corporación Nacional Forestal CONAF-Magallanes and specifically the staff of Torres del Paine National Park kindly provided support and logistics. We are also grateful to J. Seoane for help with the statistical analyses and A. Travaini for his comments on the manuscript. Funding was provided by Program UAM-CEAL (Santander Bank) during 2011-2012, 2013-2014, and 2015-2016; Foreign Affairs Ministry, Spanish Agency for Development and International Cooperation (A/9875/07, A/016431/08, and A/024945/09); Agriculture Ministry and Environment Ministry, Chile, Servicio Agrícola y Ganadero 2011-2012; and the REMEDINAL-3CM network (S2013/MAE-2719). $\mathrm{ECl}$ was supported by a PhD grant from the Spanish Ministry of Education (FPU) and is currently supported by a post-doctoral grant from National Scientific and Technical Research Council (CONICET).

\section{ORCID}

Esperanza C. Iranzo iD http://orcid.org/0000-0001-9411-8437

Heiko U. Wittmer (ID http://orcid.org/0000-0002-8861-188X

Juan Traba (iD http://orcid.org/0000-0001-6326-8942

Pablo Acebes (iD http://orcid.org/0000-0003-1880-7841

Cristina Mata iD http://orcid.org/0000-0002-6206-1015

Juan E. Malo iD http://orcid.org/0000-0002-6033-5035

\section{REFERENCES}

Acebes, P., Malo, J. E., \& Traba, J. (2013). Trade-offs between food availability and predation risk in desert environments: The case of polygynous monomorphic guanaco (Lama guanicoe). Journal of Arid Environments, 97, 136-142. https://doi.org/10.1016/j. jaridenv.2013.05.017 
Bank, M. S., Sarno, R. J., Campbell, N. K., \& Franklin, W. L. (2002). Predation of guanacos (Lama guanicoe) by southernmost mountain lions (Puma concolor) during a historically severe winter in Torres del Paine National Park, Chile. Journal of Zoology, 258, 215-222. https:// doi.org/10.1017/S0952836902001334

Banks, P. B. (2001). Predation-sensitive grouping and habitat use by eastern grey kangaroos: A field experiment. Animal Behaviour, 61, 10131021. https://doi.org/10.1006/anbe.2001.1686

Barrera, K., Soto, N., Cabello, J. \& Antúnez, D. (2010). 'El puma. Antencedentes para su conservación y manejo en Magallanes'. Punta Arenas: Servicio Agrícola y Ganadero.

Barri, F., \& Fernández, M. (2011). Foraging and vigilance time allocation in a guanaco Lama guanicoe) population reintroduced in Quebrada del Condorito National Park (Córdoba, Argentina). Acta Ethologica, 14, 103-107. https://doi.org/10.1007/s10211-011-0098-5

Barton, K. (2012). MuMIn: Multi-model inference. R package version 1.7. 11.

Bates, D., Maechler, M., Bolker, B. \& Walker, S. (2011). Ime4: Linear mixed-effects models using S4 classes. http://cran.R-project.org/ package=Ime4. $R$ package version $0.999375-42$

Burnham, K. P., \& Anderson, D. R. (2002). Information and likelihood theory: A basis for model selection and inference. In Burnham and Anderson (Ed.), Model Selection and Multimodel Inference: A Practical Information-Theoretic Approach (pp. 49-97). New York, NY: Springer Science \& Business Media.

Burnham, K. P., \& Anderson, D. R. (2004). Multimodel inference understanding AIC and BIC in model selection. Sociological Methods \& Research,33,261-304. https://doi.org/10.1177/0049124104268644

Cappa, F., Campos, V., Giannoni, S., \& Andino, N. (2017). The effects of poaching and habitat structure on anti-predator behavioral strategies: A guanaco population in a high cold desert as case study. PLoS ONE, 12, e0184018. https://doi.org/10.1371/journal.pone.0184018

Caro, T. M., Graham, C. M., Stoner, C. J., \& Vargas, J. K. (2004). Adaptive significance of anti-predator behaviour in artiodactyls. Animal Behavior, 67, 205-228. https://doi.org/10.1016/j.anbehav.2002.12.007

Childress, M. J., \& Lung, M. A. (2003). Predation risk, gender and the group size effect: Does elk vigilance depend upon the behaviour of conspecifics? Animal Behaviour, 66, 389-398. https://doi. org/10.1006/anbe.2003.2217

Creel, S., Dröge, E., M'soka, J., Smit, D., Becker, M., Christianson, D., \& Schuette, P. (2017). The relationship between direct predation and antipredator responses: A test with multiple predators and multiple prey. Ecology, 98, 2081-2092. https://doi.org/10.1002/ecy.1885

Creel, S., Schuette, P., \& Christianson, D. (2014). Effects of predation risk on group size, vigilance, and foraging behavior in an African ungulate community. Behavioral Ecology, 25, 773-784. https://doi. org/10.1093/beheco/aru050

Creel, S., \& Winnie, J. A. (2005). Responses of elk herd size to finescale spatial and temporal variation in the risk of predation by wolves. Animal Behaviour, 69, 1181-1189. https://doi.org/10.1016/j. anbehav.2004.07.022

Donadio, E., \& Buskirk, S. W. (2016). Linking predation risk, ungulate antipredator responses, and patterns of vegetation in the high Andes. Journal of Mammalogy, 97, 966-977. https://doi.org/10.1093/ jmammal/gyw020

Eccard, J. A., Meißner, J. K., \& Heurich, M. (2017). European roe deer increase vigilance when faced with immediate predation risk by Eurasian Iynx. Ethology, 123, 30-40. https://doi.org/10.1111/ eth.12420

Elbroch, L. M., \& Wittmer,H.U.(2012). Puma spatial ecology in open habitats with aggregate prey. Mammalian Biology-Zeitschrift für Säugetierkunde, 77, 377-384. https://doi.org/10.1016/j.mambio.2012.02.010

Elith, J., Leathwick, J. R., \& Hastie, T. (2008). A working guide to boosted regression trees. Journal of Animal Ecology, 77, 802-813. https://doi. org/10.1111/j.1365-2656.2008.01390.x
Franklin, W. L. (1982). Biology, ecology, and relationship to man of the South American camelids. Mammalian Biology in South America, 6, 457-489.

Franklin, W. L., Johnson, W. E., Sarno, R. J., \& Iriarte, J. A. (1999). Ecology of the Patagonia puma (Felis concolor patagonica) in southern Chile. Biological Conservation, 90, 33-40. https://doi.org/10.1016/ S0006-3207(99)00008-7

Gerard, J., \& Loisel, P. (1995). Spontaneous emergence of a relationship between habitat openness and mean group size and its possible evolutionary consequences in large herbivores. Journal of Theoretical Biology, 176, 511-522. https://doi.org/10.1006/ jtbi.1995.0217

González, B. A., Palma, R. E., Zapata, B., \& Marín, J. C. (2006). Taxonomic and biogeographical status of guanaco Lama guanicoe (Artiodactyla, Camelidae). Mammal Review, 36, 157-178. https://doi. org/10.1111/j.1365-2907.2006.00084.x

Hamilton, W. D. (1971). Geometry for the selfish herd. Journal of Theoretical Biology, 31, 295-311. https://doi. org/10.1016/0022-5193(71)90189-5

Iranzo, E. C., Acebes, P., Estades, C. F., González, B. A., Mata, C., Malo, J. E., \& Traba, J. (2017). Diffusive dispersal in a growing ungulate population: Guanaco expansion beyond the limits of protected areas. Mammal Research, https://doi.org/10.1007/s13364-017-0345-x.

Iranzo, E. C., Traba, J., Acebes, P., González, B. A., Mata, C., Estades, C. F., \& Malo, J. E. (2013). Niche Segregation between Wild and Domestic Herbivores in Chilean Patagonia. PLoS ONE, 8, e59326. https://doi. org/10.1371/journal.pone.0059326

Jarman, P. (1974). The social organisation of antelope in relation to their ecology. Behaviour, 48, 215-267. https://doi. org/10.1163/156853974X00345

Johnson, W. E., \& Franklin, W. L. (1994). Spatial resource partitioning by sympatric grey fox (Dusicyon griseus) and culpeo fox (Dusicyon culpaeus) in southern Chile. Canadian Journal of Zoology, 72, 1788-1793. https://doi.org/10.1139/z94-242

$\mathrm{Kie}$, J. G. (1999). Optimal foraging and risk of predation: Effects on behavior and social structure in ungulates. Journal of Mammalogy, 80, 1114-1129. https://doi.org/10.2307/1383163

Laundré, J. W., Hernández, L., \& Altendorf, K. B. (2001). Wolves, elk, and bison: Reestablishing the" landscape of fear" in Yellowstone National Park, USA. Canadian Journal of Zoology, 79, 1401-1409. https://doi. org/10.1139/z01-094

Lehtonen, J., \& Jaatinen, K. (2016). Safety in numbers: The dilution effect and other drivers of group life in the face of danger. Behavioral Ecology and Sociobiology, 70, 449-458. https://doi.org/10.1007/ s00265-016-2075-5

Lima, S. L. (1995). Back to the basics of anti-predatory vigilance: The group-size effect. Animal Behaviour, 49, 11-20. https://doi. org/10.1016/0003-3472(95)80149-9

Lima, S. L., \& Dill, L. M. (1990). Behavioral decisions made under the risk of predation: A review and prospectus. Canadian Journal of Zoology, 68, 619-640. https://doi.org/10.1139/z90-092

Linden, D. W., Fuller, A. K., Royle, J. A., \& Hare, M. P. (2017). Examining the occupancy-density relationship for a low-density carnivore. Journal of Applied Ecology, 54, 2043-2052. https://doi. org/10.1111/1365-2664.12883

Long, E. S., Fecske, D. M., Sweitzer, R. A., Jenks, J. A., Pierce, B. M., \& Bleich, V. C. (2003). Efficacy of photographic scent stations to detect mountain lions. Western North American Naturalist, 63, 529-532.

Lucherini, M. (2016). Lycalopex culpaeus. The IUCN Red List of Threatened Species 2016: e.T6929A85324366.https://doi. org/10.2305/iucn.uk.2016-1.rlts.t6929a85324366.en Downloaded on 25 December 2016

Marino, A. (2010). Costs and benefits of sociality differ between female guanacos living in contrasting ecological conditions. Ethology, 116, 999-1010. https://doi.org/10.1111/j.1439-0310.2010.01812.x 
Marino, A., \& Baldi, R. (2008). Vigilance patterns of territorial guanacos (Lama guanicoe): The role of reproductive interests and predation risk. Ethology, 114, 413-423. https://doi. org/10.1111/j.1439-0310.2008.01485_1.x

Marino, A., \& Baldi, R. (2014). Ecological Correlates of Group-Size Variation in a Resource-Defense Ungulate, the Sedentary Guanaco. PLoS ONE, 9, e89060. https://doi.org/10.1371/journal.pone.0089060

Moll, R. J., Killion, A. K., Montgomery, R. A., Tambling, C. J., \& Hayward, M. W. (2016). Spatial patterns of African ungulate aggregation reveal complex but limited risk effects from reintroduced carnivores. Ecology, 97, 1123-1134.

Moll, R. J., Redilla, K. M., Mudumba, T., Muneza, A. B., Gray, S. M., Abade, L., ... Montgomery, R. A. (2017). The many faces of fear: A synthesis of the methodological variation in characterizing predation risk. Journal of Animal Ecology, 86, 749-765. https://doi. org/10.1111/1365-2656.12680

Novaro, A. J., Moraga, C. A., Briceño, C., Funes, M. C., \& Marino, A. (2009). First records of culpeo (Lycalopex culpaeus) attacks and cooperative defense by guanacos (Lama guanicoe). Mammalia, 73, 148-150.

Ortega, I. M., \& Franklin, W. L. (1995). Social organization, distribution and movements of a migratory guanaco population in the Chilean Patagonia. Revista Chilena de Historia Natural, 68, 489-500.

Pays, O., Benhamou, S., Helder, R., \& Gerard, J. F. (2007). The dynamics of group formation in large mammalian herbivores: An analysis in the European roe deer. Animal Behaviour, 74, 1429-1441. https://doi. org/10.1016/j.anbehav.2007.02.012

Peacor, S. D. (2003). Phenotypic modifications to conspecific density arising from predation risk assessment. Oikos, 100, 409-415. https:// doi.org/10.1034/j.1600-0706.2003.12043.x

Périquet, S., Richardson, P., Cameron, E. Z., Ganswindt, A., Belton, L., Loubser, E., \& Dalerum, F. (2017). Effects of lions on behaviour and endocrine stress in plains zebras. Ethology, 123, 667-674. https://doi. org/10.1111/eth.12638

Phillips, S. J., Anderson, R. P., \& Schapire, R. E. (2006). Maximum entropy modeling of species geographic distributions. Ecological modelling, 190, 231-259. https://doi.org/10.1016/j.ecolmodel.2005.03.026

Pisano, E. (1974). Estudio ecológico de la región continental sur del área andino patagónica. II Contribución a la fitogeografía de la zona del Parque Nacional Torres del Paine. Anales del Instituto de la Patagonia. (pp. 59-104).

Pulliam, R. H. (1973). On the advantage of flocking. Journal of Theoretical Biology, 38, 419-422. https://doi. org/10.1016/0022-5193(73)90184-7

Pulliam, H., \& Caraco, T. (1984). Living in groups: is there an optimal group size? In J. R. Krebs, \& N. B. Davies (Eds.), Behavioural Ecology: An evolutionary approach (pp. 122-148). Oxford: Blackwell Scientific Publications.

Rey, A., Novaro, A. J., \& Guichón, M. L. (2012). Guanaco (Lama guanicoe) mortality by entanglement in wire fences. Journal for Nature Conservation, 20, 280-283. https://doi.org/10.1016/j. jnc. 2012.05.004

Rinehart, K. A., Elbroch, L. M., \& Wittmer, H. U. (2014). Common biases in density estimation based on home range overlap with reference to pumas in Patagonia. Wildlife Biology, 20, 19-26. https://doi. org/10.2981/wlb.12100

Ripple, W. J., \& Beschta, R. L. (2003). Wolf reintroduction, predation risk, and cottonwood recovery in Yellowstone National Park. Forest
Ecology and Management, 184, 299-313. https://doi.org/10.1016/ S0378-1127(03)00154-3

Schroeder, N. M., Matteucci, S. D., Moreno, P. G., Gregorio, P., Ovejero, R., Taraborelli, P., \& Carmanchahi, P. D. (2014). Spatial and Seasonal Dynamic of Abundance and Distribution of Guanaco and Livestock: Insights from Using Density Surface and Null Models. PLoS ONE, 9, e85960. https://doi.org/10.1371/journal.pone.0085960

Tambling, C. J., Druce, D. J., Hayward, M. W., Castley, J. G., Adendorff, J., \& Kerley, G. I. H. (2012). Spatial and temporal changes in group dynamics and range use enable anti-predator responses in African buffalo. Ecology, 93, 1297-1304. https://doi.org/10.1890/11-1770.1

Taraborelli, P., Gregorio, P., Moreno, P., Novaro, A., \& Carmanchahi, P. (2012). Cooperative vigilance: The guanaco's (Lama guanicoe) key antipredator mechanism. Behavioural processes, 91, 82-89. https://doi. org/10.1016/j.beproc.2012.06.002

Taraborelli, P., Ovejero, R., Torres, M. M., Schroeder, N., Moreno, P., Gregorio, P., ... Carmanchahi, P. (2014). Different factors that modify anti-predator behaviour in guanacos (Lama guanicoe). Acta Theriologica, 59(4), 529-539. https://doi.org/10.1007/ s13364-014-0186-9

Thaker, M., Vanak, A. T., Owen, C. R., Ogden, M. B., \& Slotow, R. (2010). Group dynamics of zebra and wildebeest in a woodland savanna: Effects of predation risk and habitat density. PLoS ONE, 5, e12758. https://doi.org/10.1371/journal.pone.0012758

Traba, J., Iranzo, E. C., Carmona, C. P., \& Malo, J. E. (2017). Realised niche changes in a native herbivore assemblage associated with the presence of livestock. Oikos, 126, 1400-1409. https://doi.org/10.1111/ oik.04066

Venables, W. N., \& Ripley, B. D. (2002). Modern Applied Statistics with $S$, 4th ed.. New York: Springer. ISBN 0-387-95457-0. https://doi. org/10.1007/978-0-387-21706-2

Vidal, O. J., \& Reif, A. (2011). Effect of a tourist-ignited wildfire on Nothofagus pumilio forests at Torres del Paine biosphere reserve, Chile (Southern Patagonia). Bosque, 32, 64-76.

Whittingham, M. J., Swetnam, R. D., Wilson, J. D., Chamberlain, D. E., \& Freckleton, R. P. (2005). Habitat selection by yellowhammers Emberiza citrinella on lowland farmland at two spatial scales: Implications for conservation management. Journal of Applied Ecology, 42, 270-280. https://doi. org/10.1111/j.1365-2664.2005.01007.x

\section{SUPPORTING INFORMATION}

Additional Supporting Information may be found online in the supporting information tab for this article.

How to cite this article: Iranzo EC, Wittmer HU, Traba J, Acebes P, Mata C, Malo JE. Predator occurrence and perceived predation risk determine grouping behavior in guanaco (Lama guanicoe). Ethology. 2018;00:1-9.

https://doi.org/10.1111/eth.12727 